\title{
KEPASRAHAN HIDUP TOKOH \\ DALAM CERPEN "TUJUAN: NEGERI SENJA" KARYA SENO GUMIRA DAN “SEHARI MENUNGGU MAUT” KARYA ERNEST HAMINGWAY
}

\section{THE SURRENDER OF FIGURE'S LIFE \\ IN SHORT STORY "TUJUAN: NEGERI SENJA" BY SENO GUMIRA A AND SHORT STORY "SEHARI MENUNGGU MAUT" BY ERNEST HAMINGWAY}

\author{
Rika Istianingrum ${ }^{1}$, Yunita Suryani ${ }^{2}$, N Yeffa Afnita $A^{3}$, Siti Umi Hanik ${ }^{4}$ \\ Universitas Balikpapan ${ }^{1}$, Universitas Ronggolawe Tuban², \\ Universitas Islam Nusantara Bandung ${ }^{3}$, Universitas Gresik ${ }^{4}$ \\ Pos-el: rika@uniba-bpn.ac.id ${ }^{1}$, you.n1t4@gmail.com², yefaafnita@gmail.com³, \\ hany.akasah@gmail.com ${ }^{4}$
}

*) Naskah diterima: 7 April 2020; direvisi: 17 April 2020; disetujui: 22 Mei 2020

\begin{abstract}
Abstrak
Kepasrahan merupakan salah satu bentuk dari eksistensi hidup manusia. Seperti pada tokoh dalam cerpen "Tujuan: Negeri Senja" karya Seno Gumira Ajidarma dan cerpen "Sehari Menunggu Maut" karya Ernest Hamingway yang memilih pasrah dalam memandang kematian. Tujuan penelitian dalam artikel ini untuk memberikan deskripsi perbedaan dan persamaan mengenai makna kepasrahan yang dialami seorang tokoh dalam cerpen "Tujuan: Negeri Senja" karya Seno Gumira Ajidarma dan cerpen "Sehari Menunggu Maut" karya Ernest Hamingway. Metode yang digunakan adalah metode deskriptif dengan analisis komparatif dengan teori psikologi sastra. Teknik pengumpulan data adalah studi pustaka dengan sumber data berupa cerpen "Tujuan: Negeri Senja” karya Seno Gumira Ajidarma dan cerpen "Sehari Menunggu Maut" karya Ernest Hamingway. Teknik analisis dengan deskriptif interpretatif. Hasil yang ditemukan dalam penelitian ini adalah pada kedua cerpen tersebut terdapat persamaan tema cerita yaitu kematian. Perbedaanya terletak pada karakter tokoh dalam memaknai kepasrahan dengan sikap merelakan, menerima, mengatasi sesuatu, dan melakukan tindakan.
\end{abstract}

Kata kunci: eksistensi, kepasrahan, tokoh, cerita pendek

\begin{abstract}
Surrender is one form of existence of human life. As in the characters in the short story "Tujuan: Negeri Senja" by Seno Gumira Ajidarma and the short story "Sehari Menunggu Maut" by Ernest Hamingway who chose resignation in looking at death. The purpose of the research in this article is to provide a description of the differences and similarities regarding the meaning of surrender experienced by a character in the short story "Tujuan: Negeri Senja" by Seno Gumira Ajidarma and the short story "Sehari Menunggu Maut" by Ernest Hamingway. The method used is descriptive method with comparative analysis with literary psychology theory. Data collection techniques are literature study with data sources in the form of short stories "Tujuan: Negeri Senja" by Seno Gumira Ajidarma and the short story "Sehari Menunggu Maut" by Ernest Hamingway. Analytical techniques with interpretive
\end{abstract}


descriptive. The results found in this study are in the two short stories there are similarities in the theme of the story that is death. The difference lies in the character's character in interpreting surrender by giving up, accepting, organizing something, and taking action.

Keywords: existence, surrender, character, short stories

\section{PENDAHULUAN}

Kepasrahan merupakan salah satu kebermaknaan hidup dalam diri manusia. Manusia mempunyai karakter atau sikap yang bermacam-macam dalam memahami kebermaknaan dalam kehidupan mereka. Salah satunya dengan sikap kepasrahan yang menjadi suatu pilihan dalam menjalani kehidupan. Sikap pasrah yang menjadi karakter manusia dipicu adanya permasalahan ataupun cara pandang manusia dalam memaknai kehidupan mereka.

Sikap pasrah tidak jauh berbeda dengan sikap nrimo atau menerima dalam falsafah Jawa (Jong, 1976:19). Ketika manusia sedang mengalami kesusahan ataupun kesulitan, mereka selalu menerima hal tersebut dengan kepasrahan. Kepasrahan yang dimaksud adalah usaha untuk berdamai dalam keadaan apapun. Sikap pasrah pada karakter manusia termasuk salah satu bentuk eksistensi diri pada manusia itu sendiri.

Berkaitan dengan sikap pasrah tersebut, berdamai dengan keadaan serta memaknai keberadaan diri manusia yang menjadi pilihan hidup manusia dijelaskan pula oleh Istianingrum (2014:1) bahwa kehidupan yang bermakna akan dimiliki seseorang bila dia mengetahui apa makna dari sebuah pilihan hidupnya. Seseorang memilih sikap pasrah dan kemudian menjadikan hidup manusia tersebut bermakna atau memilih hidup yang memberontak. Hal demikian merupakan sebuah karakter atau sikap dari manusia untuk menghendaki hidup bermakna.

Pasrah mempunyai arti bahwa manusia menyerahkan sepenuhnya terhadap takdir ataupun terhadap keputusan seseorang. Kepasrahan artinya perihal pasrah. Sikap pasrah adalah sebuah keyakinan untuk menyerahkan sepenuhnya (KBBI, 2020; Suseno, 1984:16). Kepasrahan biasanya merujuk pada seseorang ketika mengalami situasi atau kondisi tanpa berusaha mengubah, memprotes, atau keluar dari kondisi tersebut. Kepasrahan sebagai salah satu bentuk karakter orang yang memersepsikan keputusasaan. Namun, jika ditelaah dengan benar berkaitan dengan persepsi kejiwaan serta karakter orang, kepasrahaan tidak hanya sekadar putus asa serta tidak dapat berusaha untuk mengubah, tetapi juga sebagai bentuk penyerahan diri setelah usaha atau ikhtiar yang dilakukan oleh orang. Persepsi tersebut membuat seseorang mempunyai pandangan yang berbeda terkait memaknai kepasrahan pada diri masing-masing.

Setiap tokoh memiliki karakteristik yang berbeda. Melalui tokoh-tokoh tersebut pengarang menggambarkan peristiwa atau kejadian yang terjadi pada kehidupan manusia. Perbedaan karakter tokoh sangat memengaruhi terjadinya peristiwa-peristiwa yang menarik di dalam karya sastra. Pada kedua cerita pendek yakni cerita pendek "Tujuan: Negeri Senja” karya Seno Gumira Ajidarma dan cerita pendek "Sehari Menunggu Maut" karya Ernest Hamingway mempunyai karakter atau watak yang berbeda dan dipengaruhi oleh dua budaya dari dua negara yang berbeda. Tokoh dalam cerita pendek "Tujuan: Negeri Senja" karya Seno Gumira Ajidarma tentu saja berasal dari Jawa yang memiliki karakter atau 
watak serta sifat dan sikap pasrah, nrimo keadaan setiap ada permasalahan yang menimpa mereka sedangkan tokoh dalam cerita pendek "Sehari Menunggu Maut" karya Ernest Hamingway berasal dari Irlandia.

Dijelaskan pula oleh Pradnyana, Artawan, Sutama mengenai aspek-aspek kejiwaan manusia bahwa karya sastra selalu terlibat dalam segala aspek hidup dan kehidupan, tidak terkecuali aspek kejiwaan atau psikologi (2019:340). Pengarang selalu menampilkan tokoh yang memiliki karakter sehingga karya sastra juga menggambarkan kejiwaan. Seperti karakter tokoh dalam menyikapi sikap kepasrahan terhadap kehidupan yang mereka jalani dalam cerita pendek "Tujuan: Negeri Senja" karya Seno Gumira Ajidarma serta sikap kepasrahan hidup manusia dalam menerima keadaan sebenarnya kemudian dijadikan sesuatu yang berlebihan dalam cerita pendek "Sehari Menunggu Maut" karya Ernest Hamingway.

Melalui sebuah cerita, yakni cerita pendek "Tujuan: Negeri Senja" karya Seno Gumira Ajidarma dan cerita pendek "Sehari Menunggu Maut" karya Ernest Hamingway, pengarang menjelaskan bagaimana cara memaknai kejiwaan seorang tokoh dalam menyikapi bentuk sebuah kepasrahan hidup yang telah dilalui oleh para tokoh dalam kehidupan mereka meskipun dalam kedua cerita pendek tersebut mempunyai perberdaan yakni dilihat dari budaya, karakter, persepsi, serta cara pandang terhadap kehidupan. Hal demikian diperlukan sebuah kajian bandingan untuk membandingan segala hal di antara kedua bentuk perbedaan tersebut di dalam kedua cerita yang berbeda budaya serta berbeda negara yang berkaitan dengan cara memaknai sikap kepasrahan yang dialami oleh para tokoh dalam cerita pendek “Tujuan: Negeri Senja" karya Seno Gumira Ajidarma dan cerita pendek "Sehari Menunggu Maut" karya Ernest Hamingway.

Sastra bandingan mempelajari hubungan timbal balik karya sastra dari dua atau lebih kebudayaan nasional yang biasanya berlainan bahasa, dan terutama pengaruh karya sastra yang satu terhadap karya sastra lain (Damono, 2009:16-17). Sastra bandingan mengungkap sebuah karya mengenai perbedaan dan persamaan dari sudut pandang apapun di dalam karya sastra tersebut. Terkait kedua cerita pendek “Tujuan: Negeri Senja" karya Seno Gumira Ajidarma dan cerita pendek "Sehari Menunggu Maut" karya Ernest Hamingway, kajian bandingan sangat diperlukan untuk mengetahui segala hal yang berbeda maupun sama antara kedua karya tersebut yang tentu saja berbeda dari kultur budaya. Oleh karena itu, penelitian ini membahas mengenai perbedaan serta persamaan cara pandang karakter para tokoh dalam cerita pendek “Tujuan: Negeri Senja” karya Seno Gumira Ajidarma dan cerita pendek "Sehari Menunggu Maut" karya Ernest Hamingway dalam memaknai kepasrahan terhadap kehidupan mereka.

\section{LANDASAN TEORI}

Eksistensi manusia adalah suatu proses yang dinamis, suatu "menjadi" atau "mengada". Hal tersebut sesuai dengan asal kata eksistensi itu sendiri, yakni existere, yang artinya "ke luar dari" atau "mengatasi" dirinya sendiri (Abidin, 2007:16). Setiap orang mempunyai eksistensi yang berbeda-beda dalam kehidupannya. Bereksistensi sangat penting bagi manusia untuk dapat menyikapi segala permasalahan yang menimpa dirinya serta mendapatkan kehidupan bermakna.

Setiap manusia yang diistilahkan sebagai tokoh dalam sebuah cerita memiliki ciri khas tersendiri, sehingga pembaca dapat membedakan karakter masing-masing 
tokoh. Minderop (1996:36-37) membagi karakterisasi tokoh dalam dua bagian, (1) karakterisasi secara langsung yakni, melalui pengarang, tokoh lain, dan tokoh itu sendiri, (2) karakterisasi secara tidak langsung, yakni melalui deskripsi tingkah laku tokoh, penggambaran bentuk lahir, dan pelukisan hubungan.

Berkaitan dengan analisis karakter tokoh, peran psikologi sangat diperlukan. Demikian pula berkiatan dengan karya sastra, menghadirkan psikologi sastra dalam teori payungnya. Seperti yang dijelaskan oleh Minderop bahwa daya tarik psikologi sastra adalah pada masalah manusia yang melukiskan potret jiwanya, tidak hanya jiwa sendiri yang muncul dalam sastra, tetapi juga meawakili jiwa orang lain (2013:59). Penelitian psikologi sastra yang bertumpu pada masalah kejiwaan serta karakter manusia yakni memaknai cara pandang dalam sikap kepasrahan, merujuk pada paham psikoanalis. Psikoanalis menjadi sebuah teori yang paling komprehensif di antara teori kepribadian lainnya yang mengupas mengenai kehidupan persepsi serta karakter seseorang.

Kepasrahan adalah istilah yang sering digunakan dalam konsep agama, kerohanian, serta psikologi manusia. Pandangan keagamaan serta kerohanian dan psikologi sering mengusulkan jalur kepasrahan pada keadaan yang tidak disukai dan tidak dapat diubah atau jika terdapat perubahan hanya dimungkinkan dengan pengorbanan dan sebuah risiko yang mereka hadapi sendiri (Imam, 2005:45).

Kepasrahan merupakan sebuah sikap yang mengaharuskan seseorang untuk pasrah menerima segala sesuatu yang telah ditetapkan bagi dirinya. Jong dalam uraiannya mengenai sikap hidup orang Jawa menjelaskan bahwa sikap pasrah selalu dimiliki oleh masyarakat Jawa yang taat dengan berbagai aturan yang telah meng- ikatnya, sikap pasrah tersebut antara lain, menerima sesuatu, merelakan sesuatu, melakukan tindakan, mengatasi sesuatu, serta menyikapi sesuatu (1976:15-16).

Penelitian ini adalah penelitian komparatif, yakni membandingan sebuah persepsi karakter tokoh dalam karya sastra berkaitan dengan tingkah laku kejiwaan manusia. Penelitian komparatif ini dikaji melalui pendekatan sastra bandingan. Damono (2009:1 -3) menjelaskan bahwa sastra bandingan adalah pendekatan dalam ilmu sastra yang tidak dapat menghasilkan teori sendiri. Boleh dikatakan teori apapun bisa dimanfaatkan dalam penelitian sastra bandingan, sesuai dengan objek dan tujuan penelitiannya. Dalam beberapa tulisan, sastra bandingan juga disebut sebagai studi atau kajian. Dalam langkah-langkah yang dilakukannya, metode perbandingan adalah yang utama. Endraswara (2013:128) menjelaskan bahwa sastra bandingan adalah daerah sastra yang memaparkan hubungan karya sastra satu dengan bidang yang lainnya. Dapat kita artikan bahwa sastra bandingan merupakan studi untuk mengkaji karya sastra atau hubungan dua kesusastraana atau lebih yang biasanya berbeda bahasa.

\section{METODE PENELITIAN}

Artikel dalam penelitian ini merupakan jenis penelitian kualitatif kajian pustaka, yakni mengumpulkan data dengan memanfaatkan sumber data berupa teks cerita pendek, yaitu cerita pendek “Tujuan: Negeri Senja karya Seno Gumira Ajidarma dalam kumpulan cerita pendek Iblis Tidak Pernah Mati dan cerita pendek "Sehari Menunggu Maut" karya Ernest Hamingway (terjemahan oleh Ursula Gyani Buditjahja dari The Snows of Kilimanjaro). Data yang diambil adalah kalimat dialog atau narasi yang terdapat di dalam kedua cerita pendek tersebut yang mengacu pada fokus permasalahan peneliti- 
an, yakni perbedaan dan persamaan dalam memaknai serta menyikapi bentuk kepasrahan hidup tokohnya

Penelitian dengan metode analisis komparatif atau perbandingan harus bisa menuju pada penemuan relasi antara dua karya satra yang dibandingkan, dengan kata lain bahwa kesejajaran menjadi tumpuan analisis (Endraswara, 2011:177-178). Metode yang digunakan dalam artikel adalah metode deskriptif dengan analisis komparatif atau perbandingan. Penggunaan metode penelitian ini merujuk pada persyaratan pendekatan perbandingan sastra seperti yang dikemukakan oleh Sumiyadi, dalam artikelnya mengenai perbandingan mitos cerita Arjuna, bahwa cerita yang dibandingkan harus dalam bahasa yang berbeda (2017:803). Bahasa yang dimaksud adalah bahasa Indonesia dan bahasa Inggris atau bahasa asing yang terlebih dahulu melalui proses terjemahan.

Pendekatan yang digunakan dalam artikel penelitian ini adalah sastra komparatif. Damono menjelaskan bahwa sastra komperatif adalah pendekatan tertentu yang tidak menghasilkan teori. Oleh karena itu, teori apapun dapat digunakan dalam penelitian sastra komperatif (2009:1). Teori yang digunakan adalah teori psikologi sastra yang merujuk pada sikap atau karakter kejiwaan manusia dalam menyikapi bentuk kepasrahan dirinya terhadap kehidupan.

Teknik analisis dalam penelitian ini adalah deskriptif interpretatif yang memanfaatkan kajian bandingan serta unsur interpretatif dalam cara menganalisisnya karena unsur interpretasi tersebut merupakan landasan bagi metode deskriptif interpretatif yang berbentuk pendeskripsian (Bakker, 1990:42).

\section{HASIL DAN PEMBAHASAN}

Cerita pendek “Tujuan: Negeri Senja” karya Seno Gumira Ajidarma dan cerita pendek

"Sehari Menunggu Maut" karya Ernest Hamingway merupakan cerita menarik dan inspiratif yang berkenaan dengan eksistensi kehidupan seseorang. Kedua cerita pendek tersebut mengisahkan cara pandang dan karakter seseorang dalam memaknai kepasrahan atas kematian yang mereka alami sebagai takdir. Kepasrahan tokoh yang terdapat dalam kedua cerita tersebut diuraikan berdasarkan beberapa aspek kepribadian sikap pasrah, yakni menerima sesuatu, merelakan sesuatu, melakukan tindakan, mengatasi sesuatu, serta menyikapi sesuatu. Kepasrahan hidup tokoh dalam cerita dan perbandingan antara cerita pendek “Tujuan: Negeri Senja" karya Seno Gumira Ajidarma dan cerita pendek "Sehari Menunggu Maut" karya Ernest Hamingway diuraikan sebagai berikut.

\section{Kepasrahan Seorang Tokoh pada Cerita Pendek "Tujuan: Negeri Senja" karya Seno Gumira Ajidarma}

Cerita pendek "Tujuan: Negeri Senja" karya Seno Gumira Ajidarma mengisahkan bahwa di stasiun Tugu, Yogyakarta, terdapat sebuah loket yang selalu sepi dari pembeli, yaitu loket yang hanya menjual tiket ke jurusan Negeri Senja. Keberadaan kota yang bernama Negeri Senja ini tidak diketahui oleh orang-orang yang akan bepergian dengan kereta api tujuan Negeri Senja. Tokoh lelaki tersebut melihat orang-orang yang akan pergi dengan kereta tujuan Negeri Senja saling berpelukan untuk melepas kepergian. Ia melihat sebuah keluarga yang akan pergi layaknya piknik bersama anak-anak mereka. Selain itu, terlihat anak remaja dengan model rambut anak punk yang seakan tidak punya semangat hidup lagi. Namun, kakek-kakek dan nenek-nenek 
terlihat bahagia ketika menunggu kereta. Mereka semua seakan pasrah dengan sesuatu hal yang akan dijumpainya di Negeri Senja. Sebenarnya apa yang ada dalam pikiran mereka, harapan kosong ataukah sebuah kematian yang mereka inginkan.

Kepasrahan seorang tokoh tampak pada orang-orang yang melakukan perjalanan dengan kereta api tujuan Negeri Senja. Sikap pasrah yang dimiliki oleh orang-orang tersebut adalah pasrah dalam merelakan sesuatu, yakni pada kalimat, "Jangan lupakan aku, ya." (2018:130). Tokoh tersebut akan pergi ke Negeri Senja dan berpamitan kepada keluarganya. Ia berpesan agar merelakan dirinya untuk pergi dan jangan melupakan dirinya. Sikap pasrah dalam menerima sesuatu pun dimiliki oleh beberapa orang anak remaja dengan gaya model rambut yang tidak tertata rapi atau eksentrik. Mereka tidak memiliki semangat dalam menjalani hidup dan hati yang terpaksa. Sikap pasrah menerima sesuatu juga tergambar pada para orang tua lanjut usia dengan hati yang bahagia, mereka pasrah ikut dalam perjalanan ke Negeri Senja. Sikap kepasrahan dengan melakukan tindakan tergambar pada sikap tokoh lelaki tersebut. Ketidaktahuannya mengenai Negeri Senja yang diberitakan oleh orang-orang, membuat dirinya ingin mengikuti perjalanan ke Negeri Senja yang dikabarkan bahwa manusia yang pergi ke Negeri Senja tidak dapat pulang kembali ke asalnya. Namun tokoh lelaki tetap dengan keinginanya untuk pergi dan tetap ingin berusaha untuk kembali pulang ke asalnya.

\section{Kepasrahan Seorang Tokoh pada Cerita Pendek "Sehari Menunggu Maut" Karya Ernest Hamingway}

Cerita pendek "Sehari Menunggu Maut" Karya Ernest Hamingway mengisahkan seorang tokoh anak lelaki berusia 9 tahun bernama Schatz sedang menderita penyakit influenza. Dokter yang merawat Schatz mengatakan bahwa suhu tubuh Schatz mencapai $102{ }^{\circ} \mathrm{C}$. Penyakit flu tersebut membuat Schatz mempunyai pikiran yang bermacam-macam yakni sebuah kematian. Schat yang masih berusia 9 tahun mempunyai pemikiran bahwa jika seorang anak mengalami sakit flu dengan suhu tubuh 44 ${ }^{0} \mathrm{C}$ maka dia tidak dapat bertahan dalam hidupnya sedangkan suhu tubuh Schatz adalah $102{ }^{\circ} \mathrm{C}$.

Pemikiran Schatz, anak usia 9 tahun bahwa jika anak-anak sedang sakit flu dengan suhu tubuh melebihi $44^{\circ} \mathrm{C}$ sedangkan suhu tubuhnya sendiri adalah $102{ }^{\circ} \mathrm{C}$, tidak dapat bertahan. Pemikiran tersebut didapatkannya dari temannya Schatz yang tinggal di Prancis. Schatz sangat ketakutan terhadap penyakit yang dideritanya, hingga membuat sang ayah bingung harus berbuat apa. Sang ayah meyakinkan Schatz bahwa sakit yang diderita Schatz tidaklah parah, hanya demam biasa dan segera sembuh jika meminum obat yang diresepkan oleh dokter. Namun, pikiran Schatz sangat terganggu, Schatz tetap tidak percaya dan tetap pasrah jika dia meninggal karena penyakitnya tersebut.

Kepasrahan tokoh dalam menerima sesuatu tergambar pada tokoh Schatz dalam kepasrahannya saat menerima sakit yang menurut diagnosis dokter tidak terlalu parah. Jiwa dan pikiran Schatz merasa terganggu karena sakit yang dia derita. Alihalih dia menerimanya dan mencoba untuk tetap semangat dalam hidupnya, Schatz justru menerima penyakitnya tersebut dengan pasrah dan yakin. Dia meyakini bahwa sakit yang dideritanya menyebabkan dirinya tidak dapat bertahan dan akan mengalami kematian. Seperti kalimat, "Berapa lama lagi sebelum aku mati?" Tanya Schatz kepada ayahnya (2001:448). Selain itu, kepasrahan yang digambarkan oleh tokoh ayah merupakan sikap mengatasi sesuatu. 
Tokoh ayah berusaha mengatasi kepasrahan tersebut dengan cara menasihati Schatz bahwa penyakit yang Schatz derita tidaklah parah. Sikap mengatasi pada tokoh ayah digambarkan pula dengan menemani Schatz dan membacakan cerita ketika Schatz terbaring lemas di tempat tidur. Kesabaran dalam mengatasi kegelisahan Schatz tersebut adalah usaha tokoh ayah dalam kepasrahannya menghadapi karakter Schatz yang ketakutan akan kematian karena penyakit flu.

\section{Persamaan dan Perbedaan Memaknai Kepasrahan Seorang Tokoh pada Cerita Pendek "Tujuan: Negeri Senja" karya Seno Gumira Ajidarma dan Cerita Pen- dek "Sehari Menunggu Maut" Karya Ernest Hamingway}

Kepasrahan seorang tokoh yang diceritakan dalam cerita pendek "Tujuan: Negeri Senja" karya Seno Gumira Ajidarma dan cerita pendek "Sehari Menunggu Maut" Karya Ernest Hamingway mempunyai kesamaan. Kesamaan yang pertama terletak pada tema sentral dari kedua cerita pendek, yakni menyikapi sebuah kematian dalam kehidupan yang dialami oleh para tokoh. Kesamaan yang lain terdapat pada karakter tokoh-tokoh dalam kedua cerita pendek tersebut. Jika dilihat dari sudut budaya, tokoh dalam cerita pendek “Tujuan: Negeri Senja" karya Seno Gumira Ajidarma merupakan masyarakat Jawa daerah Yogyakarta sedangkan tokoh-tokoh dalam cerita pendek "Sehari Menunggu Maut" Karya Ernest Hamingway merupakan warga negara Irlandia, para tokoh di dalam kedua cerita pendek tersebut mempunyai karakter yang hampir sama yakni sikap kepasrahan dalam menerima sesuatu yang dialami oleh mereka. Tokoh para orang tua dan anak remaja dalam cerita pendek “Tujuan: Negeri Senja" karya Seno Gumira Ajidarma memaknai kepasrahan dalam dirinya dengan menerima sesuatu yang telah ditakdirkan oleh Tuhan dengan rasa bahagia bagi orang tua, rasa yang tidak punya harapan untuk hidup bagi para anak remaja yaitu kematian yang disimbolkan mengikuti perjalanan ke Negeri Senja. Tokoh Schatz dalam cerita pendek "Sehari Menunggu Maut" Karya Ernest Hamingway memaknai kepasrahan dalam dirinya dengan menerima sesuatu ketika dirinya didiagnosis penyakit flu ringan yang menurut tokoh Schatz bahwa penyakit flu adalah wabah buruk hingga mengakibatkan kematian.

Perbedaan memaknai kepasrahan seorang tokoh pada cerita pendek "Tujuan: Negeri Senja" karya Seno Gumira Ajidarma dan cerita pendek "Sehari Menunggu Maut" Karya Ernest Hamingway terletak pada cara pandang para tokoh di kedua cerita pendek tersebut dalam menyikapi kepasrahan. Pada cerita pendek "Tujuan: Negeri Senja” karya Seno Gumira Ajidarma yang berlatar belakang Kota Yogyakarta tentu saja memengaruhi cara pandang masyarakat Jawa dalam menyikapi sesuatu permasalahan yaitu dengan sikap nrimo, rela. Tokoh yang terdapat pada cerita pendek tersebut yaitu anggota keluarga dengan sikap yang bahagia dan sedih harus merelakan anggota keluarganya dalam sebuah kematian yang disimbolkan dengan naik kereta tujuan Negeri Senja. Selain sikap nrimo, rela, merelakan sesuatu dalam kepasrahan, masyarakat Jawa juga ada yang bertindak sekehendak hatinya sendiri. Suseno menjelaskan bahwa masyarakat Jawa dalam melakukan sesuatu terkadang sesuka hatinya, tetapi sebuah risiko apapun tetap diambil, mau tidak mau, akhirnya tetap juga memasrahkan keadaan dirinya kepada Tuhan (1984:205). Memaknai kepasrahan dengan sikap melakukan tindakan terlihat pada tokoh lelaki yang merasakan keanehan dalam kereta api tujuan Negeri Senja. Tokoh 
lelaki tersebut dengan berani dan segala risiko, dia bertindak untuk ikut naik dan berpikir harus bisa kembali ke tempat asalnya, kembali dari sebuah kematian. Berbeda dengan masyarakat luar Indonesia yaitu masyarakat Irlandia dalam menghadapi permasalahan sebuah kematian atau penyakit. Pada cerita pendek "Sehari Menunggu Maut" Karya Ernest Hamingway kepasrahan seorang tokoh digambarkan dalam tokoh ayah Schatz. Tokoh ayah ketika dihadapkan pada kenyataan bahwa putranya sakit terkena wabah flu tidak serta merta sedih atau merelakan anaknya karena penyakit anaknya hanya demam ringan. Kepasrahan yang dilakukan oleh tokoh ayah adalah dengan mengatasi sesuatu. Tokoh ayah menasihati anaknya agar tetap tenang ketika sedang menderita penyakit flu. Tokoh ayah juga membacakan cerita untuk anaknya agar anaknya tidak gelisah dalam menghadapi pengakit flu ringan. Tokoh ayah sangat optimis dan mempunyai karakter yang positif ketika mengetahui anaknya demam ringan.

\section{PENUTUP}

Cara pandang para tokoh dalam cerita pendek “Tujuan: Negeri Senja” karya Seno Gumira Ajidarma dan cerita pendek "Sehari Menunggu Maut" Karya Ernest Hamingway ketika memaknai kepasrahannya memiliki beberapa karakter. Karakter tersebut mencakup berbagai aspek yakni, merelakan sesuatu, menerima sesuatu, melakukan tindakan, serta mengatasi sesuatu dalam permasalahan kehidupan mereka. Karakter para tokoh yang terdapat di dalam kedua cerita pendek tersebut menyiratkan kebermaknaan hidup setiap tingkah laku mereka.

Adapun persamaan para tokoh dalam memaknai kepasrahan hidupnya dalam cerita pendek "Tujuan: Negeri Senja" karya Seno Gumira Ajidarma dan cerita pendek
"Sehari Menunggu Maut" Karya Ernest Hamingway terletak pada sikap karakter mereka dalam menerima sesuatu hal ketika dihadapkan pada sebuah takdir kematian serta penyakit. Perbedaan para tokoh dalam memaknai kepasrahan hidup dalam cerita pendek "Tujuan: Negeri Senja" karya Seno Gumira Ajidarma terletak pada cara bersikap dalam menerima kepasrahan sedangkan dalam cerita pendek "Sehari Menunggu Maut" Karya Ernest Hamingway terletak pada sikap yang tidak gampang menyerah atas takdir, tetapi lebih pada berpikir untuk mengatasi sesuatu dengan pikiran yang optimis.

\section{DAFTAR PUSTAKA}

Abidin, Zainal. 2007. Analisis Eksistensial. Jakarta: PT Raja Grafindo Persada.

Ajidarma, Seno Gumira. 2018. Iblis Tidak Pernah Mati. Yogyakarta: Yayasan Galang.

Bakker, Anton dan Achmad Charris Zubair. 1990. Metodologi Penelitian Filsafat. Yogyakarta: Kanisius.

Damono, Sapardi Djoko. 2009. Sastra Bandingan. Jakarta: Editum.

Endraswara, Suwardi. 2011. Metode Penelitian Sastra Bandingan. Jakarta: Bukupop.

Endraswara, Suwardi. 2013. Metodologi Penelitian sastra; Epistemologi, metode, Teori, dan Aplikasi. Jakarta: Caps.

Hamingway, Ernest. 2001. Salju Kilimanjaro. (terjemahan oleh Ursula Gyani Buditjahja dan Melani Budianta dari buku The Snows of Kilimanjaro). Jakarta: Yayasan Obor Indonesia.

Imam S, Suwarno. 2005. Konsep Tuhan, Manusia, Mistik dalam Berbagai Kebatinan Jawa. Jakarta: PT. Raja Grafindo Pertama. Istianingrum, Rika. 2014. "Eksistensi dan Makna Hidup Tokoh Lesbian dalam Novel Karya Lesbian Penulis". Surabaya: Universitas Negeri Surabaya. 
Jong, De. 1976. Salah Satu Sikap Orang Jawa. Sumiyadi, S. 2017. The Arjuna Myth within Yogyakarta: Yayasan Kanisius.

KBBI. 2020. Pasrah. (https:// kbbi.kemdikbud.go.id/entri/pasrah). Diakses pada 30 Mei 2020.

Minderop, Albertine. 1996. Metode Karakterisasi Telaah Fiksi. Jakarta: Yayasan Pustaka Obor Indonesia.

Minderop, Albertine. 2013. Psikologi Sastra: Karya Sastra, metode, teori, dan Contoh Kasus. Jakarta: Yayasan Obor Indonesia.

Pradnyana, I Wayan Gede, dkk. Psikologi Tokoh dalam Novel Siti Karya Sapardi Joko Damono: Anlisis Psikologi Sastra. Jurnal Ilmu Pendidikan \& Pembelajaran 3 (3): 339-347. Bali: Universitas Pendidikan Ganesha. Two Indonesian Novels and One Sundanese Novel: A Comparative Literature Analysis. In The Tenth Conferenece on Applied Linguistic and The Second English language teaching and Technology Conference in collaboration with The First International Conference on Language, Literature, culture, and Education (CONAPLIN and ICOLLITE 2017), 802-807. Bandung: Universitas Pendidikan Indonesia.

Suseno, Franz Magnis. 1984. Etika Jawa: Sebuah Analisa Falsafi tentang Kebijakan Hidup Orang Jawa. Jakarta: Gramedia. 